(C)old beginnings and technologies of rectification in early years education: the implications for teachers and children with special educational needs

Done, Elizabeth

http://hdl.handle.net/10026.1/12767

10.1080/09669760.2018.1547633

International Journal of Early Years Education

Taylor \& Francis (Routledge)

All content in PEARL is protected by copyright law. Author manuscripts are made available in accordance with publisher policies. Please cite only the published version using the details provided on the item record or document. In the absence of an open licence (e.g. Creative Commons), permissions for further reuse of content should be sought from the publisher or author. 


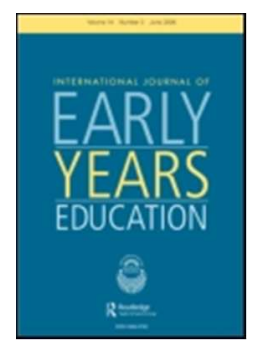

(C)old beginnings and technologies of rectification in early years education: the implications for teachers and children with special educational needs

\begin{tabular}{|r|l|}
\hline Journal: & International Journal of Early Years Education \\
\hline Manuscript ID & CIEY-2018-0010.R2 \\
\hline Manuscript Type: & Original Article \\
\hline Keywords: & Early years education, Inclusion, Special educational needs, Deleuze, Policy \\
\hline \multicolumn{2}{|r}{} \\
\hline
\end{tabular}

SCHOLARONE $^{\text {m }}$

Manuscripts 


\title{
(C)old beginnings and technologies of rectification in early years education: the implications for teachers and children with special educational needs
}

\begin{abstract}
This paper considers varied governmental initiatives in England and their implications for early years education, including: an Office for Standards in Education (2017) report entitled 'Bold beginnings' proposing curriculum changes in Reception teaching based on identified features of a small number of 'good' and 'outstanding' schools; Department of Education (2014) advice for early years providers on special educational needs; and proposals from the same department for a single statutory baseline test in Reception. All assume a linear model of child development conceived as 'progress' and reflect moves to codify all aspects of child learning and early years professional practice. An alternative view of early years education drawn from poststructuralism is suggested here that affords more scope for intuitive practice and professional judgement in a child-centred approach.
\end{abstract}

Key words: early years education; special needs; Deleuze; child-centredness.

\section{Introduction}

Guidance relating to special educational needs and disabilities (SEND) in England is outlined in the latest SEND Code of Practice $0-25$ years issued by the Departments of Health and for Education (DoH / DfE 2015). Earlier advice directed specifically at early years education (EYE) providers (DfE 2014) notes the pivotal role of early years practitioners in realising the vision enshrined in the Children and Families Act 2014 (Stationery Office [TSO] 2014) upon which the revised Code is based. The key elements of this role are summarised as the early identification of additional needs, the provision of appropriate support and the fostering of aspiration in an outcomes-driven system; notably, long-term change in educational culture is stated to be conditional upon the confidence and skills of practitioners (DfE 2014, 3). Whilst such statements can be read as political affirmation of the deeply-held conviction of early years practitioners and researchers that EYE can determine, or significantly influence, the future academic attainment and life trajectories of young people (MacNaughton 2004), the key argument presented in this paper is that such political affirmation signals a two-fold political process that radically alters understandings of 
professional knowledge and judgement, transformational learning experiences and, indeed, of childhood itself.

\section{A poststructuralist perspective}

We will consider this two-fold process and the implications of governmental expectations that early years practitioners can, and must, deliver quantifiable progress in specified areas of child development. Drawing primarily on Deleuze and Guattari (2004), and related texts, we critically frame this process as educational hylomorphism. It is suggested that early years teachers and their pupils are discursively constructed as passive, that is, as if they were formless inert material waiting to be shaped by external agencies. This occurs through a political educational discourse comprising policy papers, statutory guidance and school inspection regimes which, unsurprisingly, also supply templates stipulating what constitutes the teaching role and pupil progress within EYE. Whereas MacNaughton (2004) argues that a 'politics of logic' now pervades early childhood research and policy, we maintain that the valorisation of linear causality evidenced in political educational discourse is equally suggestive of the Platonic concept of the matter-form relation as outlined by Protevi (2001, 7). Many EYE practitioners tacitly perpetuate such valorisation and it is now applied to early years teachers themselves as we explain below.

\section{Hylomorphism}

A hylomorphic conceptualisation of production, whether it is 'progress' or sanctioned teaching practice or schools that meet government expectations which is being produced, implies the top-down imposition of a pre-given form upon passive matter. Protevi $(2001,8)$ characterises hylomorphism as 'arche-thinking' in which 'a simple unchanging commanding origin' is presented as 'responsible for change in others'. As such, it is a denial of multiplicity and immanence whereby change is produced relationally, that is, through changes in the immanent relations and the forces at play within a social field. As Protevi (2001) notes, this 
hylomorphic doctrine forecloses the possibility of nuanced pragmatic experimentation that responds to the singular features of the matter in question.

Philosophical thought has always influenced, and continues to influence, pedagogic theory and practice and educational policy (Peters and Tesar 2017), and hylomorphism is clearly evidenced in the conception of the child as a tabula rasa or blank sheet that can be inscribed according to social priorities. The difficulty here is that this hylomorphic conception makes it impossible to think about the contribution of the child to the educational process or how teachers might respond intuitively to the singularities of the pupils that they encounter as implied in the concept of child-centredness (UNESCO 1994) or, more recently, personalised learning (Scott 2015).

Contrary to the Platonic conception of matter as inert or passive, Deleuze and Guattari (2004) insist that matter should be understood as carrying singularities or implicit forms which are, in fact, variable affects or, in Protevi's $(2001,7)$ terms, potentials for selfordering. A useful example drawn from Deleuze and Guattari $(2004,450)$ is that of wood whose fibres reveal 'variable undulations and torsions of the fibres' that the artisan must respond to or negotiate and that guide the 'operation of splitting wood'; this implies that 'form must be seen as suggested by the matter rather than as the pure product of the architect's mind' (Protevi 2001, 7). There is a political dimension to this analogy when Protevi $(2001,204)$ states that "what is needed is the "artisanal" recognition of the ability to coax forth the positive contributions of material inputs to desired products'; by contrast, arche-thinking focuses only on a vision of the desired product and neglects the affectivity of contributors to the production process.

It is the teacher's capacity to coax forth positive contributions to any learning process from the child - which assumes professional judgement but also familiarity or relationship and the uniqueness of every child, that a statutory baseline test undertaken only weeks after a 
child enters school fails to acknowledge. Teaching is reduced to a teleological or outcomedriven exercise in which the standards agenda is prioritised, a narrow definition of progress is reified (Bradbury and Roberts-Holmes 2016), and in which the contexts and complexity of pedagogic practice do not feature. Neoliberal educational policy discourse bears a remarkable similarity to the Platonic doctrine of hylomorphism in that it can only command and is blind to singularities (Protevi 2001, 8). Demands for the early identification of SEND also bypass calls for a values-driven education as conceived by Biesta (2010); they position teachers as the passive recipients of skills training such that policy implementation will produce the politically desired results, that is, the identification and rectification of 'progress' deficits. Peters and Tesar $(2017,6)$ regard this current political environment as one that is likely to 'managerialise' and 'marginalise' childhood, whilst Davies (2005) has argued that neoliberal educational discourse constructs educational professionals as perpetual novices with an assumed training deficit.

\section{Defining or de-contextualising 'progress'}

The first element of the two-fold process which we have dubbed educational hylomorphism has been aptly conceptualised as the 'reification of progress' within national school monitoring and accountability procedures and the revised framework of the Office for Standards in Education (Ofsted) for school inspection (Bradbury and Roberts-Holmes 2017, 943); that is, 'progress' is presented as a real or concrete process rather than one that is constructed through a politicised educational discourse. School performance is now assessed not only on student attainment in standardised tests but also on whether expected levels of progress are achieved. All children are thereby involved in a high stakes testing regime that simultaneously reinforces an idealised linear model of child development. EYE is now to be prioritised as the site of baseline data production (DfE 2017) - the point where progress tracking begins, rather than as the site of formative and potentially transformative educational 
experience. Inclusion based on the child-centred education envisaged in the Salamanca Statement (UNESCO 1994) has been replaced as an organising principle by a political discourse in which child development is reduced to the achievement of stipulated degrees of progress in narrowly defined subject areas. Additionally, according to the DfE (2014) and SEND Code statutory guidance (DoH / DfE 2015), interventions must be provided to children who deviate from governmentally prescribed levels of progress in order to minimise that deviation. EYE has become a key component of an 'outcomes-driven system' (DfE 2014, 3) in which teachers are no longer free to judge which outcomes really matter for a particular child or school. The current Conservative government's proposed introduction of a single statutory baseline test in Reception (DfE 2017) disregards research such as that of Bradbury and Roberts-Holmes $(2016,5)$. In that research, teachers argue that existing baseline assessment 'has little use in terms of the identification of additional needs' (5). Consequently, it is teachers and schools that must undertake the task of assimilating isolated policy areas.

\section{De-professionalising EYE}

The second element of this political process of educational hylomorphisation can be described as a de-professionalising of teachers (removed for review purposes). Following Davies (2005), this involves the repeated discursive construction of educational practitioners as novices, accompanied by their mandatory participation in a complex set of training, monitoring and accountability practices. The DfE (2014) report which prioritises early identification of additional needs in EYE exemplifies this tendency to present successful policy implementation as largely a matter of teachers acquiring confidence and skills. Issues such as the freedom to exercise professional judgement and the availability of adequate funding or external support services when required are consequently side-lined. The implication of the DfE (2014) report is that the early identification of additional needs in EYE is dependent on teachers acquiring codified competences that they are assumed to lack 
and that must be incorporated into their practice in order to address this purported deficit. The report fails to acknowledge teachers' awareness of the frequently uneven development or learning of young children and the potentially negative consequences on the self-esteem of young children of being labelled 'SEN'. Such knowledge and legitimate concerns around labelling are pre-empted and foreclosed when inclusion is presented as a matter of the future training of early years practitioners regardless of how much professional experience they possess.

\section{Recent developments in EYE}

Unlike the Early Years Foundation Stage (EYFS) profile introduced under a previous Labour government which is restricted to the identification of areas for development (Standards and Testing Agency [STA] 2016), the baseline reception test which is likely to become statutory in 2020 is designed to permit national comparison of test scores and measurement of the child's progress (i.e. school performance) when leaving primary school (STA 2017). Testing will cover literacy, numeracy and communication and language but may also include the capacity for self-regulation. Ironically, given the affirmation of early years practitioners' pivotal role noted above, assessment based on teacher observation will not feature in this proposed testing regime (Ward 2017). The price of political affirmation of the pivotal role of EYE is the inclusion of young children in a politicised standards agenda that reduces them to providers of performance data with the attendant risks of a narrowed curriculum. The direction of travel is confirmed in a recent Ofsted (2017) report which construes 'Bold beginnings' in Reception as an enhanced emphasis on literacy and numeracy; such an emphasis can be interpreted as likely to diminish the time allowed for play even though play is widely regarded as integral to early learning (Magnusson and Pramling 2018; Nolan and Paatsch 2018). 
The unstated assumption in the advice directed towards EYE providers (DfE 2014) is that familiarity with statutory requirements and acquisition of the skills required to fulfil them will result in confident practitioners who are able and willing to enact the policy enshrined in the latest SEND Code of Practice (DoH / DfE 2015). A key feature of this Code is a shift of responsibility such that teachers are now responsible for all children in their class, including those with SEND, whilst Special Educational Needs Coordinators (SENCos) are charged with the strategic leadership of SEND-related change and the development of an inclusive ethos across their setting. The remit of the SENCo now includes ensuring that practitioners within their setting are familiar with their statutory responsibilities, identifying skill gaps and organising appropriate training. Teachers who have achieved SENCo accreditation following university-based training report increased confidence. However, contrary to the DfE (2014) advice, small-scale setting-based research undertaken by SENCos undertaking such training indicates that repeated training exercises can raise awareness of this shift in responsibility and associated SEND identification procedures; but they do not necessarily produce a similar increase in confidence in applying this knowledge in the classroom. Such findings seemingly speak to concerns around the failure to provide post-qualification training for early years professionals (Marshall, Ralph and Palmer 2002; Mroz and Hall 2003); but they contradict the link between awareness, skills and confidence that is assumed in the DfE's (2014) advice directed to EYE providers. In the following section, we explore why this may be the case and suggest that research findings around, and governmental constructions of, confidence deficits may be masking resistance to what Campbell-Barr $(2018,76)$ has described as 'the "know and fix" mentality of policy makers', and concomitant silencing of 'the views and experiences of ECEC [early childhood education and care] professionals'.

\section{Cold beginnings}


The assumption that the acquisition of knowledge and skills will inevitably produce confidence is suggestive of the crude linear causality that MacNaughton (2004) argues is frequently evidenced in discourse around EYE; it is the same model of causality which is exemplified when neuroscientific research is mobilised to highlight the critical role of EYE in subsequent child development and academic attainment. MacNaughton (2004) suggests that early years practitioners have interpreted such research findings as a form of professional recognition that can also function as political capital in debates around funding within the education sector. In reality, the links between SEND-related interventions which are marketed as founded on scientific research and peer-reviewed basic scientific findings are often tenuous (Rose 1990; 2007, 29-30); such reported findings cannot precisely predict outcomes for an individual child or dictate the form that applications of such findings should take in EYE settings; this remains largely a matter of professional judgement or intuition. MacNaughton (2004) argues against the reductionism that linear causality implies and for an alternative poststructuralist logic which acknowledges the complexity of learning environments and contingency of outcomes. Deleuze and Guattari (2004) provide such an alternative and their conceptualisation of the brain neatly illustrates the contrast between linear causal logics and the poststructuralist preference for multiplicity. Deleuze and Guattari (1994) viewed the brain and its formation of neural pathways as exemplifying open and probabilistic systems, that is, ones where particular outcomes may be likely but are never guaranteed and can be unpredictable. The processes involved are suggestive of a material self-ordering (Protevi 2001) that, when considered in the context of EYE, implies a pedagogy that recognises both the positive contribution of the child to any educational process and the intuitive aspect of professional judgement.

The same positivistic and reductionist causal logic criticised by MacNaughton (2004) now pervades governmental reports, policy texts and guidance, and political discourse concerning 
education. It is integral to a marketised educational sector that is characterised by what Ball (2003) terms 'soulless performativity', where every aspect of child development is scrutinised and quantified, and the performance of educational practitioners and their settings is similarly scrutinised through various accountability procedures. Peformativity implies public demonstrations of effectiveness, conceived in linear causal terms. The associated performance data must permit comparison of teachers and schools if it is to carry disciplinary power (Foucault 1977, 1982); or if it is to exercise what Deleuze (1995) viewed as political control of dividualised (de-individualised) objects of scrutiny.

The forthcoming single statutory baseline test (DfE 2017) is designed to replace the three currently approved and non-mandatory tests: BASE, which is computer-based and from Durham University's Centre for Evaluation and Monitoring; EExBA, from the Early Excellence training organisation which is based on teacher observations; and the Reception Baseline Assessment from the National Foundation for Educational Research which combines tasks and observations (Ward 2017). The governmental objective is to create a floor standard that $65 \%$ of schools are required to meet (DfE 2016, 2017). In the political discourse around standards, a mandatory standardised baseline test ostensibly generates reliable comparative data such that claims about the raising of schools performance nationally are viewed as well-founded.

The move to only one standardised mandatory baseline test will mean that schools will no longer have the freedom to select an assessment that is deemed appropriate to their context. The DfE's preference for a test which may, following a tender process, be computer-assisted (Ward 2017) follows ministerial dismay that the majority of schools had elected for the EExBA assessment which relies on the observation and professional judgement of teachers (Ward 2016). Ironically, it is precisely the professional judgement of Reception and early years teachers - once they are skilled up and acquire confidence, that the government insists 
should be relied on in the early identification of additional needs (DfE 2014); this is despite the simultaneous discursive construction of teachers in other policy documents as producing potentially unreliable assessments (Ward 2016; DfE 2017, 4, 13, 19, 31) such that standardised testing must be introduced. In the Ministerial Foreword to the DfE (2017) report, Justine Greening, does refer to 'teachers' professionalism' but also describes what a future assessment regime should look like; the implication here is that current assessment practices may not be offering an appropriate degree of reliability and trustworthiness - a theme evidenced throughout the report:

I am clear that our primary assessment system must be fit for purpose and sustainable. It must produce data that is reliable and trusted, so that progress can be measured fairly and accurately (DfE 2017, 4).

The discourse around inclusion, like that around raising standards, is characteristically neoliberal in its future-orientation and implies a grossly over-simplified version of causality. Historically, both features were evidenced in Ofsted's SEND Review (2010) which attributed failures in inclusion to poor teaching. Teachers are repeatedly presented as both problem and solution within neoliberal political discourse, suggesting a two-fold hylomorphism in which teachers must orchestrate politically desired change in the student population whilst simultaneously being acted upon as a teaching body in order that the form of both meets political expectations.

In an analysis of 'audit cultures' and high-stakes testing in the U.K., U.S.A. and Australia, Thompson and Cook $(2013,243-244)$ consider the generation of data for performance measurement and situate such measurement within 'an international education reform trajectory that aims to promote quality and equity as articulated through a particular logic of good education, good policy and "good teaching"'. The U.K. version of 'good teaching' is 'quality first teaching', as specified in statutory guidance relating to SEND (DoH / DfE 
2015). It is similarly couched in a neoliberal discourse that, ultimately, justifies the codification of teaching practice as a matter of national economic performance and priorities. Perhaps echoing McNaughton's (2004) cautionary note about the risks of seeking political recognition, Thompson and Cook $(2013,244-245)$ also suggest that the full implications of this discursive shift have not been grasped; and this is despite the now routine invoking in educational discourse of a terminology of efficiency, effectiveness, transparency, performance and accountability (245).

This changing manifestation of 'good teaching in education policymaking, however, has not resulted in a corresponding change in the way teachers conceive and practise 'good teaching'. Most teachers continue a tradition of 'good teaching' that precedes and succeeds an audit culture. Teachers are most likely yet to appreciate the change to the logics of 'good teaching' that result within audit cultures. (Thompson and Cook 2013, 244).

The proposed standardised and statutory baseline test at Reception stage signals the incorporation of EYE into an audit culture in which the 'complexity of multiple possibilities' (Thompson and Cook 2013, 244) is rationalised such that 'only that which is measurable is important (Apple 2005, 11). It is questionable whether children with 'special' or additional needs will benefit from such a data-driven environment. High stakes testing regimes threaten the pastoral dimension of the teaching role (Thompson and Cook 2014) and risk exacerbating, rather than reducing, inequities within education ((Thompson and Cook 2012). Curricula tend to become narrower as schools and teachers are evaluated on pupil performance in core subjects. As McNaughton (2004) suggests, an emphasis on outcomebased education works to alter how pastoral care is conceived and provided. Early identification of additional needs in EYE is likely to lead, for example, to selected children's participation in highly structured interventions that are ostensibly designed to foster self- 
regulation but involve numerical scoring systems (linked to appropriate and inappropriate behaviours) that meet governmental demands that progress must be calculated and displayed. It is also useful to note that the latest SEND Code of Practice (DoH / DfE 2015) incorporates practices, such as increased and structured parental engagement, which were trialled in the Achievement for All initiative (Department for Children, Schools and Families 2009). This initiative was designed to raise the performance of and improve the wider outcomes of pupils with SEND. In a subsequent evaluative study (Humphrey and Squires 2011, 16-17), it was explicitly acknowledged that such practices were resource-intensive and were therefore likely to require additional provision, and that contextual factors would determine whether the reported progress could be replicated beyond the participating schools; it was similarly acknowledged that some groups of pupils with additional or 'special' needs, for example, those with autism, responded to varying degrees. In Ofsted (2017), it is emphasised that the sample of 41 'good' or 'outstanding' schools upon which its recommendations are based contains many which are located in socio-economically deprived areas; presumably this is intended to pre-empt criticism that contextual factors are neglected. However, there is no explicit reference to pupils with SEND and only one paragraph, reproduced below in its entirety, devoted to children who fall behind their peers, which appears under the header 'Interventions':

Importantly, when children were not as quick to pick up knowledge and understanding as others, they were given the extra support needed to help them keep up with their peers or catch up quickly when they arrived later in the school year. Interventions were not about introducing new teaching methods to see if they would work better. Instead, the existing content was broken down into smaller steps and children were given more time to practise and embed their new learning. (Ofsted 2017, 18). 
The lack of clarity and detail here and in the Ofsted (2017) report more generally - for example, in content related to the time which should be dedicated to play in Reception, is worrisome on several counts. Ofsted (2017) conveniently ignores the disproportionate representation of children with special needs (of varying degrees of complexity and severity) in some schools such that resourcing a high level of 'extra support' may prove challenging for many. The cursory and seemingly dismissive treatment of interventions also contradicts the statutory guidance outlined in the SEND Code of Practice (DoH / DfE 2015); the Code obliges teachers to introduce appropriate interventions and provide evidence of having done so prior to seeking referral to external support services where children do not progress at a stipulated rate. Historically, this graduated approach was designed to address an alleged problem of over-identification of special needs in the school population linked to funding mechanisms (DfE 2011; removed for review purposes). When considered against the Ofsted (2017) report, we begin to understand why some teachers may lack confidence in implementing statutory advice around SEND (DoH / DfE 2015; DfE 2014); teachers are required to ensure early identification whilst avoiding over-identification in a political climate where failure to do both risks feeding a discourse of poor teaching (Ofsted 2010). Now, Ofsted (2017) appears to be discouraging interventions on the grounds that they permit teachers to engage in pragmatic experimentation with different teaching methods, risking deviation from the model of 'good' practice and curriculum design that it wishes to promote. Ofsted's (2017) key recommendation is that Reception should involve more formal direct whole class teaching focusing on literacy. Despite statements about the importance of maintaining a broad and balanced curriculum, the time allocated to play in the study schools is never specified. Play is presented as facilitating only social and emotional development and less of a priority than aligning the Reception curriculum more closely with that of Year 1. 
This contradicts wider recognition of the importance of play in EYE and child learning (Nolan and Paatsch 2018).

It is unclear why Ofsted (2017) assumes that a statutory baseline reception test will avoid teaching to the test (Thompson and Cook 2014) given the former's criticism of the EYFS profile on the grounds that teachers design activities around profile assessment areas.

Similarly, its acknowledgment of excessive teacher workloads is confined to recognition that the evidence gathering required for the EYFS profile is onerous. Ofsted (2017) simply fails to explore the implications, for children in Reception, of being incorporated into an education culture in which pupil performance is repeatedly quantified; and where both teachers and pupils are reduced to suppliers of performance data for accountability purposes. The deprofessionalising of early years teachers is evidenced in the failure of Ofsted (2017) and governmental advice (DfE 2014) to acknowledge teachers' objections to EYE being constructed as a site for the early identification of SEND; and for the delivery of interventions which reinforce a dominant norm and create a pressure on children to learn at a similar rate to their peers or risk stigmatisation. Early years teachers on mandatory SENCo accreditation programmes are acutely aware of the potential effect of labelling on young children and have deeply held views about the nature of childhood and function of EYE. Objections to statutory advice in this area are not solely based on concerns about work load and inspection-related 'data-readiness' (Bradbury and Roberts-Holmes 2016, 948). They are based on professional experience of uneven or irregular rates of progress and convictions that children must be afforded a space in which to develop without being subject to the pressures that attend 'creating an Ofsted story' (Bradbury and Roberts-Holmes 2016) and what, with reference to DfE (2014) and DoH / DfE (2015) statutory guidance, we might dub 'creating a SEND-management story'. The issue then is no longer one of confidence and skills but, rather, it is a question of hearing the dissenting voices of such early years teachers and 
affording them a role in policy formation. Regrettably, this seems unlikely given the global reach of educational performativity and the prevailing political discourse around national economic priorities that supports numerous and varied accountability practices.

\section{Intuitive practice}

To return to the suggestion that teaching, as an intuitive practice, involves a certain 'surrendering to' and 'following of' the singularities of the child in question, Deleuze and Guattari $(2004,451)$ conceive this process as the 'connecting of operations to a materiality, instead of imposing a form upon a matter':

Of course, it is always possible to 'translate' into a model that which escapes the model; thus, one may link the materiality's power of variation to laws adapting a fixed form and a constant matter to one another. But this cannot be done without a distortion that consists in uprooting variables from the state of continuous variation, in order to extract from them fixed points and constant relations. (Deleuze and Guattari 2004, 451)

In contrast to the assumption of linear and predictable child development, Deleuze and Guattari $(2004,451)$ suggest that materiality possesses a 'nomos' (an unstructured or nomadic distribution). This concept of nomos speaks to the contingent and often unpredictable character of learning and child psycho-emotional development, but also to the intuitive aspect of early years teaching practice. Nomos, unlike logos (regular distributions structured according to some law), implies something that defies articulation or codification according to predefined schemas. When we refer to intuitive professional judgements, we are suggesting that this is not simply a matter of applying a demarcated knowledge base as in Campbell-Barr's (2018) sociological model of practice. Exactly how knowledge informs practice depends on the teacher's reading of the singularities of a particular child which, in turn, will influence decisions about how to proceed. The teaching and learning process has a 
pre-conscious or unconscious and affective dimension; and, as Massumi (2002) argues, we are looking in the wrong place if we look for thought in the head.

The intuitive professional practice that child-centred 'following' assumes can be conceived in poststructuralist terms as the negotiation of complexes of complexity, where these complexes include: pedagogic theories and loyalties, educational values and ethics, varied and conflicting governmental imperatives and policies, prior professional experiences and the children themselves (removed for review purposes). The term 'negotiation' is sufficiently non-specific to embrace the concept of 'operations' as nomos, i.e. of practice as something irreducible to existing and politically sanctioned schema. The 'know and fix' strategies referred to by Campbell-Barr $(2018,76)$, and exemplified in demands for the early identification of SEND when stipulated degrees of progress are not achieved, work to foreclose discussion around the caring dimension of EYE and diminish the scope for the exercising of professional judgement. We would also argue that there is nothing 'bold' or novel about Ofsted's (2017) attempt to effectively eliminate a traditionally defining feature of EYE. Rather, its recommendations assume that such education should serve a political standards agenda to the potential detriment of young children, just as the pressures on early years professionals to identify special or additional needs neglects their concerns about the effect of labelling through standardised testing and SEN identification at a very early age. Proposals for a single statutory baseline test in Reception similarly erode the scope for professional judgement and the freedom of schools to evolve their own strategies to support learning and well-being in diverse student populations.

\section{Technologies of rectification}

The teachers in EYE that we encounter in university-based training for the SENCo role do not oppose all forms of assessment but follow Cooper (2008) in recognising the importance of relationships within educational settings which, by definition, take time to establish. 
Writing of pupils designated as having SEBD (social, emotional and behavioural difficulties), Cooper states: 'Positive adult-pupil relationships often act as protective and remedial factors in the lives of young people with SEBD' (2008: 18). The latest SEND Code of Practice (DoH / DfE 2015) replaces the category of SEBD with that of SEMH (social, emotional, mental health) which is interpreted as implying wider concern for the well-being of all pupils. These teachers also suggest that special needs tend to become apparent over time once relationships with students have been established. Student-centredness is understood as compassionate attention to the individual needs of those students rather than the orchestration of what Slee (2015, p.10), following Rose (1990), describes as ‘technologies of optimisation' and we would dub technologies of rectification.

The type of interventions critiqued by MacNaughton (2004), and which claim to be informed by neuro-science, rely on a familiar and prescriptive linear concept of age-related psycho-emotional development and 'progress' such that remediation is deemed necessary for children falling short of age-related expectations in this area. These interventions can be extended to a whole school approach and this tends to occur in schools based in areas of high socio-economic deprivation, suggesting a selective logic of remediation that functions as a form of social management and control, and diverts attention away from social and educational inequalities. The scant content devoted to interventions in the aforementioned Ofsted (2017) report and proposed statutory single baseline test in Reception (DfE 2017) suggest that a more transmissional pedagogy is to be introduced to EYE as an alternative to student-centredness and the compassionate pedagogy and professional judgement that it facilitates. It is widely accepted that transmissional pedagogy, which assumes that children learn through passively absorbing knowledge imparted in pre-planned lessons, is no longer fit for purpose; evidence suggests that alternative pedagogic models, including personalised and 
collaborative learning, will 'better support acquisition of twenty-first century skills' (Scott $2015,1)$.

\section{Ethical statement}

Prior to our concluding remarks, it can be noted that all of the research undertaken by teachers on the National Award for Special Educational Needs Coordination at the university in question was conducted following British Educational Research Association (BERA 2011) ethical guidelines. We have referred to research in this article only where consent was given to share findings and comments in an anonymised manner.

\section{Conclusions}

EYE can now be read as a key site in which a 'politics of logic' (MacNaughton 2004), theories of child development and pedagogic theory and practice are brought into sharp relief. The technicist view of EYE teaching promoted through varied policies and in existing and proposed statutory guidance has been conceptualised here, following Deleuze and Guattari (2004), as evidencing a Platonic hylomorphism in which both teachers and children are conceived as passive recipients of pre-determined and prescribed educational models. An alternative conceptualisation of EYE teaching as 'following' (Deleuze and Guattari 2004, 450) has been outlined which recognises both the intuitive dimension of teaching and the positive contribution of children to the teaching and learning process. Poststructuralist theory affords a space in which a child-centred EYE pedagogy can be considered outside of governmental agendas and the technologies of rectification associated with Platonic 'archethinking' (Protevi 2001, 8). The 'reification of progress' posited by Bradbury and RobertsHolmes $(2017,943)$ within national school inspection and pupil performance monitoring frameworks is now also evidenced in interventions directed at children with special needs; the latter are judged against similarly reified and linear notions of age-appropriate psychoemotional development. 
A recent Ofsted (2017) report which appears to be dismissive of interventions in the event of unacceptable age-related academic progress simply advises that content is broken down into smaller steps for such children in a recommended curriculum that focuses on literacy and is to be delivered through more direct transmissional whole class instruction. Simultaneously, teachers in EYE in England are charged with early identification of SEN and the introduction of appropriate interventions to address progress deficits (DfE 2014; DoH / DfE 2015).

Research undertaken in university-based accreditation programmes for EYE teachers becoming SENCos suggests that the reported lack of confidence amongst teachers in applying their awareness of statutory guidance and specific needs, despite repeated training exercises, may in fact be a form of resistance to this confused policy landscape. It is a landscape which threatens to diminish professional autonomy (Thompson and Cook 2013, 244) and the freedom of schools to select the methods of assessment that they deem appropriate; and one in which the concepts of child-centredness (UNESCO 1994) or personalised learning (Scott 2015) may be replaced in response to governmental pressures on EYE teachers to adopt a traditionally conservative model of whole class direct teaching in a narrowed curriculum.

\section{Acknowledgements}

We would like to thank teachers on the National Award for Special Educational Needs Coordination Programme (removed for review purposes University, U.K.) who consented to their research findings and comments being referred to in this article. We would also like to thank the reviewers of the article for their constructive and helpful feedback.

\section{References}

Apple, M. 2005. Education, Markets and an Audit Culture. Critical Quarterly 47 (1-2): 11 29. 
Biesta, G.J.J. 2010. Why ‘What Works’ Still Won’t Work: From Evidence-based Education to Value-based Education. Studies in Philosophy and Education 29 (5): 491-503.

Bradbury, A. and Roberts-Holmes, G. 2016. They Are Children... Not Robots, Not Machines: The Introduction of Reception Baseline Assessment National Union of Teachers. http://www.teachers.org.uk/files/baseline-assessment--final-10404.pdf

Bradbury, A. and Roberts-Holmes, G. 2017. Creating an Ofsted Story: The Role of Early Years Assessment Data in Schools' Narratives of Progress. British Journal of Sociology of Education 38 (7): 943-955.

British Educational Research Association (2011) Ethical Guidelines for Educational Research. London: BERA.

Campbell-Barr, V. 2018. The Silencing of the Knowledge-base in Early Childhood Education and Care Professionalism. International Journal of Early Years Education 26 (1): 75-89. doi: $10.1080 / 09669760.2017 .1414689$

Cooper, P. 2008. Nurturing Attachment to School: Contemporary Perspectives on Social, Emotional and Behavioural Difficulties. Pastoral Care in Education 26 (1): 13-22. doi: $10.1080 / 02643940701848570$

Davies, B. 2005. The (Im)possibility of Intellectual Work in Neoliberal Regimes. Discourse: Studies in the Cultural Politics of Education 26 (1): 1-14.

Deleuze, G. 1995. Negotiations. 1975-1990. New York: Columbia University Press.

Deleuze, G. and Guattari, F. 1994. What is Philosophy? London: Verso.

Deleuze, G. and Guattari, F. 2004. A Thousand Plateaus. London: Continuum. 
DfCSF (Department for Children, Schools and Families) 2009. Achievement For All: Guidance for Schools. Nottingham: DfCSF Publications.

DfE (Department for Education) 2011. Support and Aspiration: A New Approach to Special Educational Needs and Disabilities: A Consultation (The Green Paper). London: DfE.

DfE (Department for Education) 2014. Early Years: Guide to the 0 to 25 SEND Code of Practice. London: DfE.

DfE (Department for Education) 2016. Educational Excellence Everywhere. London: DfE.

DfE (Department for Education) 2017. Primary Assessment in England Government Consultation Response: September 2017.

https://www.gov.uk/government/uploads/system/uploads/attachment_data/file/644871/Primar y_assessment_consultation_response.pdf

DoH / DfE (Department of Health and Department for Education) 2015. SEND Code of Practice 0 - 25 Years. London: DfE.

Removed for review purposes 2015.

Foucault, M. 1977. Discipline and Punish. London: Allen Lane.

Foucault, M. 1982. The Subject and Power. Critical Inquiry 8 (Summer 1982): 777-795. 
Humphrey, N. and Squires, G. 2011. Achievement For All: National Evaluation: Final Report. DFE-RR176. London: DfE.

Magnusson, M. and Pramling, N. 2018. In 'Numberland': Play-based Pedagogy in Response to Imaginative Numeracy. International Journal of Early Years Education 26 (1): 24-41. doi: $10.1080 / 09669760.2017 .1368369$

Marshall, J., Ralph, S. and Palmer, S. 2002. 'I Wasn't Trained to Work With Them':

Mainstream teachers' Attitudes to Children with Speech and Language Difficulties. International Journal of Inclusive Education 6(3): 199-215.

Massumi, B. 2002. Parables for the Virtual: Movement, Affect, Sensation. Durham: Duke University Press.

MacNaughton, G. 2004. The Politics of Logic in Early Childhood Research: A Case of the Brain, Hard Facts, Trees and Rhizomes. http://files.eric.ed.gov/fulltext/EJ689638.pdf

Mroz, M. and Hall, E. 2003. Not Yet Identified: The Knowledge, Skills and Training Needs of Early Years Professionals in Relation to Children's Speech and Language Development. Early Years 23 (2): 117-130.

Removed for review purposes 2016. 
Nolan, A. and Paatsch, L. 2018. (Re)affirming Identities: Implementing a Play-based Approach to Learning in the Early Years of Schooling. International Journal of Early Years Education 26 (1): 42-55. doi: 10.1080/09669760.2017.1369397

Ofsted 2010. The Special Educational Needs and Disability Review: A Statement is Not Enough. Manchester: Ofsted.

Ofsted 2017. Bold Beginnings: The Reception Curriculum in a Sample of Good and Outstanding Primary Schools. Manchester: Ofsted.

Peters, M. and Tesar, M. 2017. The Philosophy of Early Childhood: Examining the Cradle of the Evil, Rational and Free Child. In Troubling the Changing Paradigms: An Educational and Philosophy and Theory Early Childhood Reader, Volume IV, edited by Peters, M. and Tesar, M., 2-15. Abingdon: Routledge.

Protevi, J. 2001. Political Physics: Deleuze, Derrida and the Body Politic. London: Athlone.

Rose, N. S. 1990. Governing the Soul: The Shaping of the Private Self. London: Routledge.

Rose, N. 2007. The Politics of Life Itself. Biomedicine, Power and Subjectivity in the TwentyFirst Century. Princeton, NJ: Princeton University Press.

Scott, C.L. (2015) The Futures of Learning 3: What Kind of Pedagogies For The TwentyFirst Century? Paris: UNESCO. 
Slee, R. 2015. Beyond a Psychology of Student Behaviour. Emotional and Behavioural

Difficulties 20(1): 3-19. doi: 10.1080/13632752.2014.947100

Standards and Testing Agency 2016. Early Years Foundation Stage Profile: 2017 Handbook. www.gov.uk/government/publications/early-years-foundation-stage-profile-handbook.

Standards and Testing Agency 2017. 14 September 2017: Schools.

https://www.gov.uk/government/publications/sta-assessment-update-14-september-2017/14$\underline{\text { september-2017-schools }}$

Thompson, G. and Cook, I. 2012. Spinning in the NAPLAN Ether: 'Postscript on the Control Societies' and the Seduction of Education in Australia. Deleuze Studies 6 (4): 564-584

Thompson, G. and Cook, I. 2013. The Logics of Good Teaching in an Audit Culture: A Deleuzian Analysis. Educational Philosophy and Theory 43 (3): 243-258.

Thompson, G. and Cook, I. 2014. Manipulating the Data: Teaching and NAPLAN in the Control Society. Discourse: Studies in the Cultural Politics of Education 35(1)|: 129-142.

TSO (The Stationary Office) 2014. Children and Families Act 2014. Norwich: TSO.

UNESCO 1994. The Salamanca statement and Framework on Action for Special Needs Education. Paris: UNESCO. 


\begin{abstract}
Ward, H. 2016. Baseline Assessments Dropped as Accountability Measures in Major DfE Uturn. Times Educational Supplement, 7 April 2016. https://www.tes.com/news/schoolnews/breaking-news/baseline-assessments-dropped-accountability-measures-major-dfe-uturn
\end{abstract}

Ward, H. 2017. DfE Planning to Spend $£ 10$ million on Reception Baseline Test. Times Educational Supplement, 21 November 2017. https://www.tes.com/news/school$\underline{\text { news/breaking-news/dfe-planning-spend-ps10m-reception-baseline-test }}$ 